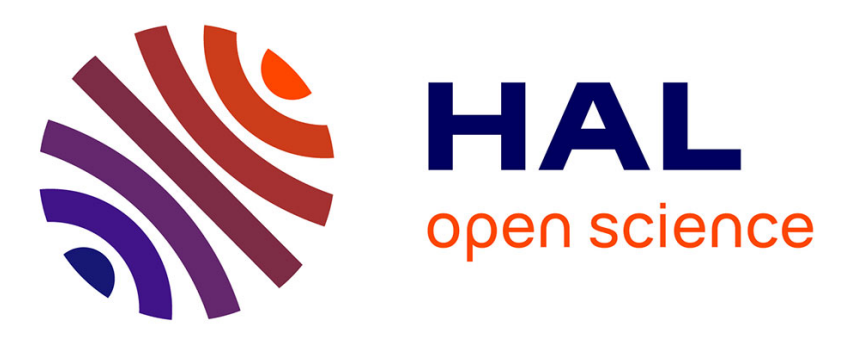

\title{
Overview of aldosterone-related genetic syndromes and recent advances
}

\author{
Maria-Christina Zennaro, Fabio Fernandes-Rosa, Sheerazed Boulkroun
}

\section{To cite this version:}

Maria-Christina Zennaro, Fabio Fernandes-Rosa, Sheerazed Boulkroun. Overview of aldosteronerelated genetic syndromes and recent advances. Current Opinion in Endocrinology, Diabetes and Obesity, 2018, 25 (3), pp.147-154. 10.1097/MED.0000000000000409 . inserm-03554660

\section{HAL Id: inserm-03554660 https://www.hal.inserm.fr/inserm-03554660}

Submitted on 3 Feb 2022

HAL is a multi-disciplinary open access archive for the deposit and dissemination of scientific research documents, whether they are published or not. The documents may come from teaching and research institutions in France or abroad, or from public or private research centers.
L'archive ouverte pluridisciplinaire HAL, est destinée au dépôt et à la diffusion de documents scientifiques de niveau recherche, publiés ou non, émanant des établissements d'enseignement et de recherche français ou étrangers, des laboratoires publics ou privés. 


\title{
Overview of Aldosterone-related Genetic Syndromes and Recent Advances
}

Maria-Christina Zennaro ${ }^{1,2,3}$, Fabio Fernandes-Rosa ${ }^{1,2,3}$, Sheerazed Boulkroun ${ }^{1,2}$

\author{
Affiliations: \\ Génétique, Paris, France \\ Address correspondence to: \\ Maria-Christina Zennaro, $\mathrm{MD}, \mathrm{PhD}$ \\ INSERM, U970 \\ Paris Cardiovascular Research Center - PARCC \\ 56, rue Leblanc, \\ 75015 Paris - France \\ Tel : +33(0)15398 8042 \\ Fax : + $33(0) 153987952$ \\ e-mail: maria-christina.zennaro@inserm.fr
}

${ }^{1}$ INSERM, UMRS_970, Paris Cardiovascular Research Center, Paris, France

${ }^{2}$ Université Paris Descartes, Sorbonne Paris Cité, Paris, France

${ }^{3}$ Assistance Publique-Hôpitaux de Paris, Hôpital Européen Georges Pompidou, Service de

\section{Disclosures}

The authors have nothing to disclose. 


\section{Abstract}

Purpose of review: Primary aldosteronism is the most common form of secondary hypertension. Early diagnosis and treatment are key to cure of hypertension and prevention of cardiovascular complications. Recent genetic discoveries have improved our understanding on the pathophysiology of aldosterone production and triggered the development of new diagnostic procedures and targeted treatments for PA.

Recent findings: Different inherited genetic abnormalities distinguish specific forms of familial hyperaldosteronism. Somatic mutations are found not only in aldosterone producing adenoma leading to primary aldosteronism, but also in aldosterone producing cell clusters of normal and micronodules from image-negative adrenal glands. Genetic knowledge has allowed the discovery of surrogate biomarkers and specific pharmacological inhibitors. Aging appears to be associated with dysregulated and relatively autonomous aldosterone production.

Summary: New biochemical markers and pharmacological approaches may allow pre-operative identification of somatic mutation carriers and use of targeted treatments.

Keywords: hypertension, adrenal, primary aldosteronism; ion channels; calcium 


\section{Introduction}

1

2 Aldosterone-related genetic syndromes encompass diseases related to abnormal aldosterone

3 production or abnormal aldosterone effects in target organs. Given the important role of

4 aldosterone in regulating sodium and potassium balance and blood pressure in the kidney, their main clinical manifestations are arterial hypertension or salt wasting and dehydration. Different diseases affect aldosterone production in the adrenal cortex. There exist several Mendelian forms of hyperaldosteronism, termed familial hyperaldosteronism (FH) type I to IV, which share most of the phenotype but show some peculiarities. They are due to gain of function mutations in ion channels and pumps, leading to increased and autonomous aldosterone production. Somatic mutations in the same genes leading to FH have been identified in aldosterone producing adenoma (APA) leading to primary aldosteronism (PA). Increased aldosterone production can also be due to monogenic forms of adrenal insufficiency affecting cortisol production, while loss-of-function mutations in $C Y P 11 B 2$, coding for aldosterone synthase, lead to aldosterone deficiency, also called corticosterone methyloxidase deficiency; those syndromes will be treated elsewhere in this section. On the other hand, different monogenic disorders affect aldosterone action in target tissues. They include a rare disease of aldosterone resistance in peripheral tissues named pseudohypoaldosteronism type 1 as well as excessive mineralocorticoid action due to different mechanisms either directly or indirectly related to aldosterone. In this review we will focus on primary aldosteronism as genetic disease strictu sensu related to aldosterone biosynthesis in the adrenal gland and then describe some emerging concepts related to pathophysiological aldosterone production.

(Figure 1)

\section{The genetics of primary aldosteronism}


PA is the most frequent form of secondary arterial hypertension. It is due to aldosterone production from the adrenal cortex relatively autonomous from the renin-angiotensin system, due in most cases to APA or bilateral adrenal hyperplasia. Its prevalence is estimated to be around $4 \%$ of all hypertensive patients seen in primary care (1), data recently confirmed in a large prospective study (2), and $10 \%$ in patients referred to tertiary care centers (1). Starting from 2011, important progress has been made in our understanding of the genetic mechanisms involved in PA. Currently, four Mendelian forms of PA, transmitted as autosomal dominant traits, have been identified (these are reviewed in detail in $(3,4)$ ). FH-I, also known as glucocorticoid remediable aldosteronism (5), is due to the formation of a chimeric gene between the highly homologous genes $C Y P 11 B 1$, coding for 11b-hydroxylase, and $C Y P 11 B 2$, coding for aldosterone synthase (6), leading to ACTH-dependent aldosterone production. Mutations in $K C N J 5$ have been identified in patients with FH-III, a severe form of familial hyperaldosteronism associated to massive bilateral hyperplasia (7), but in some cases presenting as a mild form of the disease without adrenal abnormalities (3). Germline heterozygous mutations in CACNA1D (encoding the L-type calcium channel Cav1.3 subunit alpha-1D) have been identified in patients with PA, seizures and neurological abnormalities, a rare disease called PASNA (8). Finally, mutations in CACNA1H (encoding the pore-forming $\alpha 1$ subunit of the T-type voltage-dependent calcium channel Cav3.2) have recently been reported as a cause of a new form of inherited PA, called FH-IV, associated in some cases with developmental disorder $(9,10)$. In addition, germline mutations in the same gene have been associated with mild forms of PA in patients diagnosed as FH-II (10). FH-II is indistinguishable from apparently non-familial PA and only diagnosed on the basis of two or more affected individuals in the same family (11). Despite linkage to 7p22 in one family (12), no causative locus has been identified so far. Given that germline $K C N J 5$ and $C A C N A 1 H$ mutations have been identified in patients diagnosed as FH-II, and that the clinical phenotype 
of FH-II is heterogeneous, being associated to APA as well as bilateral adrenal hyperplasia, it is reasonable to suspect that the disease may encompass different genetic syndromes.

In addition to germline variants, somatic mutations in $\operatorname{KCNJ5}(7)$ and $C A C N A 1 D(8,13)$, but also ATPases $(A T P 1 A 1$ and ATP2B3 $(13,14)$ have been identified in APA. Mutations in all these genes affect aldosterone production by altering pathways involved in maintaining intracellular ionic homeostasis and cell membrane potential, ultimately leading to increased calcium signalling. In particular, mutations in $K C N J 5$, coding for the potassium channel GIRK4, affect the selectivity filter of the channel and lead to increased sodium permeability and sodium influx, cell membrane depolarization and opening of voltage-gated calcium channels, followed by increased intracellular calcium concentrations and activation of calcium signalling, the main trigger for aldosterone production (15). Similarly, mutations in ATP1A1, encoding the $\alpha 1$ subunit of the $\mathrm{Na}^{+}, \mathrm{K}^{+}$-ATPase lead to loss of pump activity and inward sodium or proton leak, which were suggested to depolarize the cell membrane and increase aldosterone production through activation of calcium signaling $(13,14)$. More recently, experiments performed in adrenocortical NCI-H295R cells failed to demonstrate modifications of intracellular calcium concentrations in the presence of mutant $\mathrm{Na}^{+}, \mathrm{K}^{+}-$ ATPase $\alpha 1$ subunits and rather suggest a mechanism involving intracellular acidification (16). The pathogenic mechanisms involved in stimulating aldosterone production in the presence of ATP1A1 mutations may therefore result from alterations in multiple pathways, possibly in relation with the multiple roles of the $\mathrm{Na}^{+}, \mathrm{K}^{+}$-ATPase as a pump but also a signal transducing platform (17). Mutations in $C A C N A 1 D$ and $C A C N A 1 H$ directly increase intracellular calcium concentrations, by modifying voltage-sensitivity and other functional properties of these voltage-gated calcium channels $(9,10)$. Similarly, $A T P 2 B 3$ mutations affecting the plasma membrane calcium-transporting ATPase 3 (PMCA3) lead to increased intracellular calcium concentrations due to loss of the physiological pump function leading to reduced calcium 
export (18). The mutations are also associated with severely depolarized membrane potential of primary adenoma cells (14), which is explained by a pathological sodium leak associated with or conducted by the mutant PMCA3 (18). This may be a consequence of the location of the majority of PMCA3 mutations, which lie next to a "PEGL" motif in transmembrane helix 4, a region involved in calcium binding and ion gating. Disturbed intracellular ionic homeostasis is suggested to cause plasma membrane depolarization, leading to opening of voltage-gated $\mathrm{Ca}^{2+}$ channels and increased $\mathrm{Ca}^{2+}$ influx driving increased $C Y P 11 B 2$ expression and aldosterone biosynthesis. Finally, somatic mutations in $C T N N B 1$, encoding $\beta$-catenin have been described in 2-5\% of APA $(19,20)$ and mutations in PRKACA (coding for the cAMP-dependent protein kinase catalytic subunit alpha) in rare cases (21). Mutations in those genes have previously been involved in cortisol producing adenoma and adrenocortical cancer; the mechanisms whereby the same mutation leads to different hormonal phenotypes remain yet to be established ((15), see below).

\section{Clinical implications of mutation detection in PA}

Mutation detection in familial forms of PA is routinely performed in some genetic laboratories and is useful for disease screening in affected families, early diagnosis and targeted treatment. In patients with APA, the challenge is represented by the detection of somatic mutations which are absent in DNA extracted from peripheral blood cells.

Correlations of any biological feature associated with a particular mutation would allow to identify mutation carriers who could be suitable candidates for adrenal vein sampling and eventually targeted treatments $(22,23)$. The most frequent somatic event in APA are KCNJ5 mutations whose frequency ranges from 13-77\%, with higher frequency in East Asian populations ((15) and references therein). CACNA1D mutations are found in up to $10 \%$ of cases, followed by $A T P 1 A 1$ and $A T P 2 B 3$ mutations. A meta-analysis of 13 studies 
investigating a total of 1636 patients confirmed previous results showing that $K C N J 5$ mutations are more frequent in women and associated with younger age, larger tumor size and higher plasma aldosterone levels (24). Genotype-specific steroid profiles have been recently associated with APA (25). By profiling 15 steroids in adrenal venous and peripheral plasma samples from 79 patients by liquid chromatography-tandem mass spectrometry, Williams et al identified a 7-steroid fingerprint (including aldosterone, 18-oxocortisol,18-hydroxycortisol, 21-deoxycortisol, corticosterone, 11-deoxycorticosterone, and cortisol) in peripheral vein plasma able to correctly classify $92 \%$ of the APA according to genotype (25). In addition, specific steroid features were identified, in particular the presence of significantly higher hybrid steroids 18-hydroxycortisol and 18-oxocortisol in patients with APA due to KCNJ5 mutations. The usefulness of this type of screening is related to the possibility of selecting patients for adrenal vein sampling, but also for developing targeted treatments for specific mutation carriers. Initial studies of mutant KCNJ5 channels showed that their pharmacology was different from that of wild type channels (22). In particular, KCNJ5 mutants were blocked by calcium-channel blockers, such as verapamil, and Na-channel blockers, such as amiloride. At high therapeutic doses ( 3 x $120 \mathrm{mg} / \mathrm{d}$ ) plasma concentrations of verapamil could be sufficient to block the most sensitive KCNJ5 mutant p.Leu168Arg (22). More recently, Scholl et al applied a high-throughput screen based on the rescue of cell lethality induced by KCNJ5 mutations. This strategy identified a series of macrolide antibiotics, including roxithromycin, that potently inhibit the mutant channels ( $\mathrm{IC}_{50}$ of $0.22 \mu \mathrm{M}$ for the KCNJ5 p.Gly151Arg mutant and 0.69 on the p.Leu168Arg) as well as $C Y P 11 B 2$ expression and aldosterone production in adrenocortical HAC15 cells (23). The authors suggest that macrolides could be useful in screening tests aimed at identifying carriers of KCNJ5 mutations, which together with peculiar imaging characteristics of these tumors (larger size, lower pre-contrast Hounsfield units on computed tomography compared with tumors carrying 
mutations in other genes (19)) could guide subtype diagnosis for surgery. Those compounds could also be used as targeted treatments in patients who are not candidates for surgery, given their long pharmacological history and safety. In a proof-of-concept Study, Caroccia et al tested the effects of clarithromycin on aldosterone biosynthesis in primary cell lines obtained from APA tissues with or without the two most common KCNJ5 mutations, p.Gly151Arg and p.Leu168Arg (26). Remarkably, clarithromycin inhibited CYP11B2 gene expression and aldosterone production in a dose-dependent manner. Further studies are warranted to show whether these effects can be translated to patients and whether macrolides or other compounds can be used to identify and treat patients with PA due to APA with KCNJ5 mutations or patients with FH-III otherwise requiring bilateral adrenalectomy to control blood pressure (27).

\section{How do APA develop?}

While the role of somatic mutations in regulating aldosterone biosynthesis has been clearly established, the origin of APA is still a matter of debate. Different studies have been published in the last few years leading to the emergence of two hypotheses for APA development, the "two hit model" and the "APCC model".

The two-hit model supports the idea of the occurrence of two consecutive events leading to APA, a first one driving abnormal cell proliferation followed by a second one driving specific hormonal secretion. Adrenal cortex remodelling, reduced vascularization and ZG hyperplasia are major features of APA development $(28,29)$. In many cases, the resected adrenal gland harbours not only one adenoma but other micro- or macronodules, some of them expressing aldosterone synthase $(28,30,31)$. Investigation of genetic abnormalities in multinodular adrenals revealed the presence of different somatic APA driver mutations in different nodules from the same adrenal $(31,32)$, strongly suggesting that mutations are a second event 
occurring in a previously remodelled adrenal cortex. In many cases, APA have been described to be heterogeneous with aldosterone synthase expressed only in some parts of the tumour $(33,34)$; somatic mutations appear to be present only in the aldosterone synthase positive region of the APA (33). The recent description of a patient with PA harbouring a germline heterozygous $A P C$ gene mutation associated, in the resected multinodular adrenal, to biallelic APC inactivation due to a loss of heterozygosity in all nodules, but a somatic $K C N J 5$ mutation only in the aldosterone synthase expressing nodule further supports the two-hit model for APA development (35). APC is part of the WNT/ $\beta$-catenin pathway which plays a major role in adrenal gland development and tumorigenesis (36). In APA, somatic mutations in $C T N N B 1$, encoding $\beta$-catenin, are present in a subset of APA $(19,20)$ and the WNT/ $\beta$ catenin pathway is activated in two thirds of cases, independently of the mutation status (37, 38). This pathway may therefore constitute the first event leading to abnormal cell proliferation and adenoma formation. Other signalling pathways and transcriptional cascades may also be involved and create a propitious environment for the occurrence of mutations in one of the APA driver genes.

On the other hand, the APCC model supports the idea that occurrence, in ZG cells, of a somatic mutation in one of the APA driver genes leads to the formation of aldosteroneproducing cell clusters (APCC), followed, through the development of APCC-to-APA translational lesions (pAATL), to APA formation (39). Next generation sequencing performed on formalin-fixed, paraffin-embedded tissue DNA identified somatic mutations in some of the known APA driver genes, i.e. CACNA1D and ATP1A1 in 8 of 23 APCC from normal adrenals from kidney donors, most frequently affecting $C A C N A 1 D$. Interestingly, no mutation in the KCNJ5 gene, the most frequent alteration observed in APA, has been reported in APCC (39, 40). The recent description of pAATL consisting of a subcapsular APCC-like structure (APCC-like) and an inner-APA-like structure (mAPA-like) without well-defined histological 
175 border has suggested a possible APCC to APA transition (41). These specific lesions were

176 first described in adrenals from two patients with unilateral multiple adrenocortical

177 micronodules. To determine whether they could constitute intermediate structures between APCC and APA, search for mutations in APA driver genes was performed in both APCC and mAPA structures. In the first case a KCNJ5 mutation was identified in frozen tissue from a suspected aldosterone producing nodule. A different $K C N J 5$ mutation resulting in the same amino acid change was found in the mAPA-like part of a first pAATL, but not in its neighbouring APCC-like structure, indicating that the aldosterone producing nodule and the mAPA had different origins. The fact that only the mAPA portion had the mutation suggested that the mutation may have led to a transdifferentiation of the cells into a mAPA like case revealed no major abnormalities except for the presence of a pAATL (42). In a recent report of 4 additional cases, the same authors identified mutations in $K C N J 5$ preferentially found in nodules larger than $3 \mathrm{~mm}$ (41). Taken together, these results suggest that certain APCC to APA could be the result of a single-somatic mutation event or alternatively require a second-hit mutation within the APCC to promote cell proliferation. However, it has to be taken into consideration that not all mutations identified in APCCs or pAATL affect amino acids recurrently mutated in APA; those mutations therefore require functional validation for their implication in promoting aldosterone biosynthesis and eventually cell proliferation. 
In human adrenals, not all cells express $C Y P 11 B 2$, possibly reflecting high salt intake in the general population (34). Two patterns of $C Y P 11 B 2$ expression have been described in the "normal" adrenal gland: a discontinuous expression in scattered cells underneath the capsule and expression in cell clusters named $\operatorname{APCC}(28,29)$. They are composed of subcapsular zona glomerulosa-like cells and inner large zona fasciculata-like cells, expressing CYP11B2 but not CYP11B1 $(28,29)$. Despite the inner portion resembling to zona fasciculate, their transcriptome very much resembles to the transcriptome of zona glomerulosa cells, but with an enhanced capacity to produce aldosterone $(39,41)$. It has been postulated that APCC are structures of constitutive aldosterone biosynthesis, independent of renin and angiotensin II stimulation (39). This is supported by the fact that APCC in normal adrenal glands harbour somatic mutations in a subset of APA driver genes (39) and that APCC are present in the normal adrenal as well as in peritumoral tissue of adrenals with APA $(28,29)$. Of note, increased expression of the melanocortin 2 receptor (MC2R) has been reported in APCC, suggesting that adrenocorticotropic hormone (ACTH) could play a role in the regulation of aldosterone biosynthesis in APCC (39).

To assess the evolution of the adrenal cortex structure and function with time, Nishimoto et al have investigated the presence of APCC in adrenal tissues from 33 autopsied patients aged between 0 and 50 years (43). Adrenals from subjects under 11 years had layered zona glomerulosa and zona fasciculata without apparent APCC. The number and size of APCC increased with age. These results suggest either that a somatic mutation occurring in the zona glomerulosa blocks transdifferentiation to zona fasciculata and promotes APCC formation, or that APCC may develop due to aging and environmental factors, with somatic mutations being induced by unknown factors.

Based on the assumption that APCC are structures of constitutive aldosterone biosynthesis, the relation of autonomous aldosterone production, APCC and age has been investigated by 
evaluating the relationship between age and adrenal aldosterone synthase expression in 127 adrenal glands from deceased kidney donors aged 9 months to 68 years (44). This study confirmed that continuous expression of CYP11B2 was more frequent in young adrenal glands, while old adrenals very often showed discontinuous or absent zona glomerulosa CYP11B2 expression. Total and normal zona glomerulosa CYP11B2-expressing areas in the adrenal cortex were negatively correlated with age, while the area of CYP11B2 expression in APCC increased. The effect of age on aldosterone production was in parallel investigated in the HyperPATH study population, which consists of normotensive or mildly hypertensive subjects who underwent a high salt and low salt diet (45). On a high salt diet, subjects without PA showed a progressive decline of renin activity with age, while serum and 24-hour urinary aldosterone levels did not change; as a consequence, the aldosterone-to renin ratio was positively associated with older age. Under sodium restriction, the physiological stimulation of both plasma renin activity and aldosterone was blunted with increasing age. Altogether, these findings suggest a progressive pattern of abnormal aldosterone physiology with aging. The presence of APCC, which are supposedly renin-independent aldosterone producing structures, manifests with renin-independent aldosterone secretion and a decreased capacity of the adrenal gland to respond to physiological stimuli with age. The authors suggest that aging may be associated with a subclinical form of aldosterone excess. The fact that total aldosterone-expressing area in the adrenal cortex rather diminishes and aldosterone levels do not significantly change with age in the HyperPATH population rather suggests an inappropriate aldosterone production to salt status or an appropriate relatively autonomous aldosterone production.

To gain insight into how APCC evolve with age in subjects without hypertension, Omata et al investigated 107 autoptic adrenal glands using CYP11B2 immunohistochemistry and NGS and determined the APCC score and the associated somatic mutations in non-hypertensive 
patients from Japanese origin (46). The number of APCCs, which was in average 0.6 per gland, increased with age, without difference in sex distribution. 21 of 61 APCCs (34\%) showed somatic mutations in one of the APA driver genes except $K C N J 5$, with 16 affecting CACNA1D (76\%), which therefore appears to be the most frequently mutated gene in APCCs in healthy individuals from different origins (39) as well as micronodules from imagenegative adrenals removed on the basis of positive lateralization of aldosterone production at

255 AVS (40). As only one third of the genetic variants identified have previously been described in APA and functionally characterized, the consequences of the remaining somatic mutations detected in APCC warrants further examination. Remarkably, in four adrenal glands different somatic mutations were identified in individual APCCs, supporting a different clonal origin of each structure, similar to what observed in multiple nodules in multinodular adrenals with

260 APA (32). The results reported here suggest that APCC accumulation may be an agedependent phenomenon in non-hypertensive subjects, possibly explaining some cases of inappropriate aldosterone secretion not associated with hypertension. As their number was lower in normotensive compared to CT-negative PA patients (40), the authors suggest that APCC may possibly contribute to hypertension not related to PA. Whether APCC may explain some cases of low-renin hypertension requires further investigation. 
After a large number of studies identifying inherited and somatic mutations in familial hyperaldosteronism and APA, the last years have been devoted to the understanding of the functional consequences of these mutations, their possible clinical relevance and screening, and

271 the search of pharmacological approaches specifically targeting mutated proteins. Exciting new

272 knowledge has also been gathered on normal adrenal cortex structure and function in relation

273 to aldosterone production and the genetics of APCC. It can be anticipated that this knowledge

274 will be applied to patients with inherited or sporadic PA in the next few years. In addition, new

275 genes should be identified in patients with as yet unknown genetic defects, which represent half 276 of the patients harboring an APA and a large proportion of patients with familial 277 hyperaldosteronism. The causes underlying the development of bilateral adrenal hyperplasia 278 and idiopathic hyperaldosteronism remain still to be identified. 
- Four Mendelian forms of hyperaldosteronism, inherited as autosomal dominant traits, have been described

- Inherited mutations of different genes coding for ion channels and ATPases have been identified in familial hyperaldosteronism; similar somatic mutations are found in APA

- Pre-operative detection of somatic mutations may allow improved diagnosis and treatment of PA due to APA

- APCC are autonomous aldosterone-producing structures of the normal adrenal harboring somatic mutations in APA driver genes

- The aging adrenal may progressively show features of autonomous aldosterone production 
1. Acknowledgements. None.

2. Financial support and sponsorship. This work was funded through institutional support from INSERM and by the Agence Nationale pour la Recherche (ANR Blanc 2011, No.: 11-BSV1 297005 03, ANR-13-ISV1-0006-01), the Fondation pour la Recherche Médicale (DEQ20140329556), the Programme Hospitalier de Recherche Clinique (PHRC grant AOM 06179), and by grants from INSERM and Ministère Délégué à la Recherche et des Nouvelles Technologies. The laboratory of Dr. Maria-Christina Zennaro is also partner of the H2020 301 project ENSAT-HT grant $n^{\circ} 633983$.

302 3. Conflicts of interest. None.

303 


\section{References}

306

307

308 1. Hannemann A, Wallaschofski H. Prevalence of primary aldosteronism in patient's 309 cohorts and in population-based studies--a review of the current literature. Horm Metab Res. 2012 Mar;44(3):157-62. PubMed PMID: 22135219. Epub 2011/12/03. eng.

2. Monticone S, Burrello J, Tizzani D, Bertello C, Viola A, Buffolo F, et al. Prevalence and Clinical Manifestations of Primary Aldosteronism Encountered in Primary Care Practice. J Am Coll Cardiol. 2017 Apr 11;69(14):1811-20. PubMed PMID: 28385310. 2015 Dec;47(13):941-6. PubMed PMID: 26445452.

4. Fernandes-Rosa FL, Boulkroun S, Zennaro MC. Somatic and inherited mutations in primary aldosteronism. J Mol Endocrinol. 2017 Jul;59(1):R47-R63. PubMed PMID: 28400483.

5. Sutherland DJ, Ruse JL, Laidlaw JC. Hypertension, increased aldosterone secretion and low plasma renin activity relieved by dexamethasone. Can Med Assoc J. 1966 Nov 26;95(22):1109-19. PubMed PMID: 4288576. Pubmed Central PMCID: 1935810. Epub 1966/11/26. eng.

6. Lifton RP, Dluhy RG, Powers M, Rich GM, Cook S, Ulick S, et al. A chimaeric

324 11beta-hydroxylase aldosterone synthase gene causes glucocorticoid-remediable

325 aldosteronism and human hypertension. Nature. 1992;355:262-5.

327 mutations in adrenal aldosterone-producing adenomas and hereditary hypertension. Science.

328 2011 Feb 11;331(6018):768-72. PubMed PMID: 21311022. Epub 2011/02/12. eng. 
8. Scholl UI, Goh G, Stolting G, de Oliveira RC, Choi M, Overton JD, et al. Somatic and germline CACNA1D calcium channel mutations in aldosterone-producing adenomas and primary aldosteronism. Nat Genet. 2013 Sep;45(9):1050-4. PubMed PMID: 23913001. Pubmed Central PMCID: 3876926.

9. Scholl UI, Stolting G, Nelson-Williams C, Vichot AA, Choi M, Loring E, et al. Recurrent gain of function mutation in calcium channel CACNA1H causes early-onset hypertension with primary aldosteronism. eLife. 2015;4:e06315. PubMed PMID: 25907736. Pubmed Central PMCID: 4408447.

10. *Daniil G, Fernandes-Rosa FL, Chemin J, Blesneac I, Beltrand J, Polak M, et al. CACNA1H Mutations Are Associated With Different Forms of Primary Aldosteronism. EBioMedicine. 2016 Nov;13:225-36. PubMed PMID: 27729216. This study describes the presence of germline CACNA1H mutations in patients with early onset PA, familial PA diagnosed as FH-II and PA due to APA, suggesting that CACNA1H might be a susceptibility gene predisposing to PA with different phenotypic presentations.

11. Stowasser M, Gordon RD. Familial hyperaldosteronism. J Steroid Biochem Mol Biol. 2001;78(3):215-29.

12. Lafferty AR, Torpy DJ, Stowasser M, Taymans SE, Lin JP, Huggard P, et al. A novel genetic locus for low renin hypertension: familial hyperaldosteronism type II maps to chromosome 7 (7p22). J Med Genet. 2000;37(11):831-5.

13. Azizan EA, Poulsen H, Tuluc P, Zhou J, Clausen MV, Lieb A, et al. Somatic mutations in ATP1A1 and CACNA1D underlie a common subtype of adrenal hypertension. Nat Genet. 2013 Sep;45(9):1055-60. PubMed PMID: 23913004. 
secondary hypertension. Nat Genet. 2013 Apr;45(4):440-4. PubMed PMID: 23416519. Epub 2013/02/19. eng.

15. Zennaro MC, Boulkroun S, Fernandes-Rosa F. Genetic Causes of Functional Adrenocortical Adenomas. Endocr Rev. 2017 Dec 1;38(6):516-37. PubMed PMID: 28973103.

16. Stindl J, Tauber P, Sterner C, Tegtmeier I, Warth R, Bandulik S. Pathogenesis of Adrenal Aldosterone-Producing Adenomas Carrying Mutations of the $\mathrm{Na}(+) / \mathrm{K}(+)$-ATPase. Endocrinology. 2015 Dec;156(12):4582-91. PubMed PMID: 26418325.

17. Reinhard L, Tidow H, Clausen MJ, Nissen P. Na(+),K (+)-ATPase as a docking station: protein-protein complexes of the $\mathrm{Na}(+), \mathrm{K}(+)$-ATPase. Cellular and molecular life sciences : CMLS. 2013 Jan;70(2):205-22. PubMed PMID: 22695678.

**18. Tauber P, Aichinger B, Christ C, Stindl J, Rhayem Y, Beuschlein F, et al. Cellular Pathophysiology of an Adrenal Adenoma-Associated Mutant of the Plasma Membrane Ca(2+)-ATPase ATP2B3. Endocrinology. 2016 Jun;157(6):2489-99. PubMed PMID: 27035656. This is the first study addressing the mechanism of PA associated with mutations in $A T P 2 B 3$.

19. Scholl UI, Healy JM, Thiel A, Fonseca AL, Brown TC, Kunstman JW, et al. Novel Somatic Mutations in Primary Hyperaldosteronism are related to the Clinical, Radiological and Pathological Phenotype. Clin Endocrinol (Oxf). 2015 Aug 7. PubMed PMID: 26252618.

20. Akerstrom T, Maharjan R, Sven Willenberg H, Cupisti K, Ip J, Moser A, et al. Activating mutations in CTNNB1 in aldosterone producing adenomas. Scientific reports. 2016;6:19546. PubMed PMID: 26815163. Pubmed Central PMCID: 4728393. 
21. Rhayem Y, Perez-Rivas LG, Dietz A, Bathon K, Gebhard C, Riester A, et al. PRKACA Somatic Mutations Are Rare Findings in Aldosterone-Producing Adenomas. J Clin Endocrinol Metab. 2016 Aug;101(8):3010-7. PubMed PMID: 27270477.

22. Tauber P, Penton D, Stindl J, Humberg E, Tegtmeier I, Sterner C, et al. Pharmacology and pathophysiology of mutated KCNJ5 found in adrenal aldosterone-producing adenomas. Endocrinology. 2014 Apr;155(4):1353-62. PubMed PMID: 24506072.

**23. Scholl UI, Abriola L, Zhang C, Reimer EN, Plummer M, Kazmierczak BI, et al. Macrolides selectively inhibit mutant KCNJ5 potassium channels that cause aldosteroneproducing adenoma. J Clin Invest. 2017 Jun 12. PubMed PMID: 28604387. This study identifies a series of macrolide antibiotics, including roxithromycin, that potently inhibit mutated KCNJ5 channel. This discovery could have implication for diagnosis and treatment of patients with APA carriers of KCNJ5 mutations.

24. Lenzini L, Rossitto G, Maiolino G, Letizia C, Funder JW, Rossi GP. A Meta-Analysis of Somatic KCNJ5 K(+) Channel Mutations In 1636 Patients With an Aldosterone-Producing Adenoma. J Clin Endocrinol Metab. 2015 Aug;100(8):E1089-95. PubMed PMID: 26066531.

**25. Williams TA, Peitzsch M, Dietz AS, Dekkers T, Bidlingmaier M, Riester A, et al. Genotype-Specific Steroid Profiles Associated With Aldosterone-Producing Adenomas. Hypertension. 2016 Jan;67(1):139-45. PubMed PMID: 26573708. In this study, steroid profiling of adrenal vein and peripheral blood of patients with APA allowed to discriminate the mutation status with high sensitivity and specificity.

*26. Caroccia B, Prisco S, Seccia TM, Piazza M, Maiolino G, Rossi GP. Macrolides Blunt Aldosterone Biosynthesis: A Proof-of-Concept Study in KCNJ5 Mutated Adenoma Cells Ex Vivo. Hypertension. 2017 Dec;70(6):1238-42. PubMed PMID: 28993452. This study shows 
that clarithromycin was effective in reducing aldosterone production and CYP11B2 expression in primary cell cultures from APA tissues with KCNJ5 mutations.

27. Geller DS, Zhang J, Wisgerhof MV, Shackleton C, Kashgarian M, Lifton RP. A novel form of human mendelian hypertension featuring nonglucocorticoid-remediable aldosteronism. J Clin Endocrinol Metab. 2008 Aug;93(8):3117-23. PubMed PMID: 18505761. Pubmed Central PMCID: 2515083. Epub 2008/05/29. eng.

28. Boulkroun S, Samson-Couterie B, Dzib JF, Lefebvre H, Louiset E, Amar L, et al. Adrenal cortex remodeling and functional zona glomerulosa hyperplasia in primary aldosteronism. Hypertension. 2010 Nov;56(5):885-92. PubMed PMID: 20937967. Epub 2010/10/13. eng.

29. Nishimoto K, Nakagawa K, Li D, Kosaka T, Oya M, Mikami S, et al. Adrenocortical zonation in humans under normal and pathological conditions. J Clin Endocrinol Metab. 2010 May;95(5):2296-305. PubMed PMID: 20200334. Epub 2010/03/05. eng.

30. Enberg U, Volpe C, Hoog A, Wedell A, Farnebo LO, Thoren M, et al. Postoperative differentiation between unilateral adrenal adenoma and bilateral adrenal hyperplasia in primary aldosteronism by mRNA expression of the gene CYP11B2. Eur J Endocrinol. 2004 Jul;151(1):73-85. PubMed PMID: 15248825.

31. Dekkers T, ter Meer M, Lenders JW, Hermus AR, Schultze Kool L, Langenhuijsen JF, et al. Adrenal nodularity and somatic mutations in primary aldosteronism: one node is the culprit? J Clin Endocrinol Metab. 2014 Jul;99(7):E1341-51. PubMed PMID: 24758183.

32. Fernandes-Rosa FL, Giscos-Douriez I, Amar L, Gomez-Sanchez CE, Meatchi T, Boulkroun S, et al. Different Somatic Mutations in Multinodular Adrenals With AldosteroneProducing Adenoma. Hypertension. 2015 Nov;66(5):1014-22. PubMed PMID: 26351028.

Pubmed Central PMCID: 4600038. 
33. Nanba K, Chen AX, Omata K, Vinco M, Giordano TJ, Else T, et al. Molecular Heterogeneity in Aldosterone-Producing Adenomas. J Clin Endocrinol Metab. 2016 Mar;101(3):999-1007. PubMed PMID: 26765578. Pubmed Central PMCID: 4803171.

34. Gomez-Sanchez CE, Gomez-Sanchez EP. Immunohistochemistry of the adrenal in primary aldosteronism. Curr Opin Endocrinol Diabetes Obes. 2016 Jun;23(3):242-8. PubMed PMID: 27119751. Pubmed Central PMCID: 4915062.

*35. Vouillarmet J, Fernandes-Rosa F, Graeppi-Dulac J, Lantelme P, Decaussin-Petrucci M, Thivolet C, et al. Aldosterone-Producing Adenoma With a Somatic KCNJ5 Mutation Revealing APC-Dependent Familial Adenomatous Polyposis. J Clin Endocrinol Metab. 2016 Nov;101(11):3874-8. PubMed PMID: 27648962. This study describes the presence of two genetic events associated with APA formation.

36. El Wakil A, Lalli E. The Wnt/beta-catenin pathway in adrenocortical development and cancer. Mol Cell Endocrinol. 2011 Jan 30;332(1-2):32-7. PubMed PMID: 21094679. Epub 2010/11/26. eng.

37. Boulkroun S, Samson-Couterie B, Golib-Dzib JF, Amar L, Plouin PF, Sibony M, et al. Aldosterone-producing adenoma formation in the adrenal cortex involves expression of stem/progenitor cell markers. Endocrinology. 2011 Dec;152(12):4753-63. PubMed PMID: 21971159. Epub 2011/10/06. eng.

38. Berthon A, Drelon C, Ragazzon B, Boulkroun S, Tissier F, Amar L, et al. WNT/betacatenin signalling is activated in aldosterone-producing adenomas and controls aldosterone production. Hum Mol Genet. 2014 Feb 15;23(4):889-905. PubMed PMID: 24087794.

39. Nishimoto K, Tomlins SA, Kuick R, Cani AK, Giordano TJ, Hovelson DH, et al. Aldosterone-stimulating somatic gene mutations are common in normal adrenal glands. Proc Natl Acad Sci U S A. 2015 Aug 18;112(33):E4591-9. PubMed PMID: 26240369. 
*40. Yamazaki Y, Nakamura Y, Omata K, Ise K, Tezuka Y, Ono Y, et al.

Histopathological Classification of Cross-Sectional Image-Negative Hyperaldosteronism. J Clin Endocrinol Metab. 2017 Apr 01;102(4):1182-92. PubMed PMID: 28388725. This study describes high frequency somatic mutations in micronodules of image-negative PA.

41. Nishimoto K, Koga M, Seki T, Oki K, Gomez-Sanchez EP, Gomez-Sanchez CE, et al. Immunohistochemistry of aldosterone synthase leads the way to the pathogenesis of primary aldosteronism. Mol Cell Endocrinol. 2017 Feb 5;441:124-33. PubMed PMID: 27751767. Pubmed Central PMCID: 5470036.

*42. Nishimoto K, Seki T, Kurihara I, Yokota K, Omura M, Nishikawa T, et al. Case Report: Nodule Development From Subcapsular Aldosterone-Producing Cell Clusters Causes Hyperaldosteronism. J Clin Endocrinol Metab. 2016 Jan;101(1):6-9. PubMed PMID: 26580238. First report describing possible APCC-to-APA transitional lesions.

*43. Nishimoto K, Seki T, Hayashi Y, Mikami S, Al-Eyd G, Nakagawa K, et al. Human Adrenocortical Remodeling Leading to Aldosterone-Producing Cell Cluster Generation. International journal of endocrinology. 2016;2016:7834356. PubMed PMID: 27721827. Pubmed Central PMCID: 5046023 publication of this manuscript. This is the first study reporting increase in number and size of APCC with age.

**44. Nanba K, Vaidya A, Williams GH, Zheng I, Else T, Rainey WE. Age-Related Autonomous Aldosteronism. Circulation. 2017 May 31. PubMed PMID: 28566337. This study shows that aging is associated with dysregulated aldosterone synthase expression from APCC, renin-independent aldosterone secretion and a decreased capacity of the adrenal gland to respond to physiological stimuli with age.

45. Underwood PC, Chamarthi B, Williams JS, Vaidya A, Garg R, Adler GK, et al. Nonmodulation as the mechanism for salt sensitivity of blood pressure in individuals with 
470 hypertension and type 2 diabetes mellitus. J Clin Endocrinol Metab. 2012 Oct;97(10):3775-

471 82. PubMed PMID: 22865897. Pubmed Central PMCID: 3462947.

472 *46. Omata K, Anand SK, Hovelson DH, Liu CJ, Yamazaki Y, Nakamura Y, et al.

473 Aldosterone-Producing Cell Clusters Frequently Harbor Somatic Mutations and Accumulate

474 With Age in Normal Adrenals. Journal of the Endocrine Society. 2017 Jul 1;1(7):787-99.

475 PubMed PMID: 29264530. Pubmed Central PMCID: 5686701. This study shows increased

476 number and size of APCC with aging in non-hypertensive Japanese subjects.

477

478 
Figure legends.

480

481

Figure 1. Two models for APA development. Foci are composed of zona glomerulosa cells

482

where aldosterone production is under the control of its secratagogues, principally angiotensin

483

II (AngII) and potassium $\left(\mathrm{K}^{+}\right)$. On the left part of the adrenal, the "two-hit model". Local abnormal cell proliferation occurs in some zona glomerulosa cells, due to activation of specific signaling pathway such as $\mathrm{Wnt} / \beta$-catenin or shh, leading to nodule formation. Subsequently, recurrent somatic mutations in $K C N J 5, C A C N A 1 D, A T P 1 A 1$ or $A T P 2 B 3$ occur, inducing autonomous aldosterone hypersecretion and APA development. On the right part of the adrenal, the "APCC model". Somatic mutations in CACNA1D or ATPIAl lead to constitutive aldosterone production in specific structures named APCC. APCC develop into pAATL and then into APA, through abnormal cell proliferation driven by the previously described somatic mutations or by other mechanisms, which remain to be identified.

492

493

494

495 